\title{
Fecal estradiol and progesterone metabolite levels in the three-toed sloth (Bradypus variegatus)
}

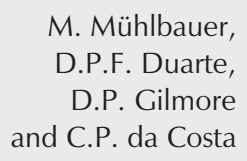

M. Mühlbauer,

D.P.F. Duarte,

D.P. Gilmore

and C.P. da Costa

Departamento de Fisiologia e Farmacologia,

Universidade Federal de Pernambuco, Recife, PE, Brasil

\section{Correspondence \\ C.P. da Costa \\ Departamento de Fisiologia e \\ Farmacologia, UFPE \\ Av. Professor Morais Rego, $\mathrm{s} / \mathrm{n}$ \\ 50670-901 Recife, PE \\ Brasil \\ Fax: +55-81-2126-8530 \\ E-mail: cpc@ufpe.br}

Research supported by FACEPE.

Received November 29, 2004 Accepted October 5, 2005

\begin{abstract}
The present study was carried out to assess the possibility of measuring fecal steroid hormone metabolites as a noninvasive technique for monitoring reproductive function in the three-toed sloth, Bradypus variegatus. Levels of the estradiol $\left(\mathrm{E}_{2}\right)$ and progesterone $\left(\mathrm{P}_{4}\right)$ metabolites were measured by radioimmunoassay in fecal samples collected over 12 weeks from 4 captive female $B$. variegatus sloths. The validation of the radioimmunoassay for evaluation of fecal steroid metabolites was carried out by collecting 10 blood samples on the same day as defecation. There was a significant direct correlation between the plasma and fecal $\mathrm{E}_{2}$ and $\mathrm{P}_{4}$ levels $(\mathrm{P}<0.05$, Pearson's test), thereby validating this noninvasive technique for the study of the estrous cycle in these animals. Ovulation was detected in two sloths (SL03 and SL04) whose $\mathrm{E}_{2}$ levels reached 2237.43 and $6713.26 \mathrm{pg} / \mathrm{g}$ wet feces weight, respectively, for over four weeks, followed by an increase in $\mathrm{P}_{4}$ metabolites reaching 33.54 and $3242.68 \mathrm{ng} / \mathrm{g}$ wet feces weight, respectively. Interestingly, SL04, which presented higher levels of $\mathrm{E}_{2}$ and $\mathrm{P}_{4}$ metabolites, later gave birth to a healthy baby sloth. The results obtained indicate that this is a reliable technique for recording gonadal steroid secretion and thereby reproduction in sloths.
\end{abstract}

Only limited information is currently available about the general endocrinology and reproductive biology of sloths (1). Little is known about courtship, mating and the duration of the estrous cycle in three-toed sloths. Gestation has long been thought to last between 6 and 8 months in Bradypus variegatus, and the inter-birth interval is thought to be 12 months (2,3). All sloth species give birth to only 1 young on each occasion. The age at which the young sloth becomes independent of its mother is about
6 months (1). It is clearly essential to investigate the reproductive parameters of these animals before loss of habitat through continued deforestation reduces sloth numbers over wide areas of their range.

Studies aimed at a better understanding of the mechanisms controlling reproduction in three-toed sloths are limited by the inaccessibility of the animals and the difficulties of maintaining them in captivity. Moreover, in the interest of conservation, noninvasive approaches should be employed as far as 
possible to monitor the situation. The only previous study carried out to investigate reproductive hormone levels in $B$. variegatus was an invasive one by Gilmore et al. (4). However, techniques for measuring the concentrations of steroid hormones and their metabolites in feces have now been widely developed, eliminating the need for capture and/or restraint of free-ranging individuals (5).

The aims of the present study were to determine whether a noninvasive method, i.e., the extraction and measurement of fecal metabolites of estradiol $\left(\mathrm{E}_{2}\right)$ and progesterone $\left(\mathrm{P}_{4}\right)$ can be validated for detecting the circulating levels of these hormones in the three-toed sloth (B. variegatus) and, if so, to use the technique to obtain information on reproductive function in this animal.

The experiments were carried out from November 2003 to August 2004 with the approval of the Ethics Committee of the Centro de Ciências Biológicas, Universidade Federal de Pernambuco, and with a license from the Instituto Brasileiro do Meio Ambiente (IBAMA, No. 02019.002944/0274).

Four sloths supplied by IBAMA were obtained from the forest in the vicinity of Recife, PE, Brazil, and kept in a vivarium close to the Department at the University for one week prior to experimental use. Upon arrival the sloths were sexed and examined to determine their health by inspection of the skin and toes and the checking of their motor activity. Initial weight and rectal temperature were recorded.

After a week at the University the animals were transported to a farm located in Aldeia, Camaragibe, PE, Brazil, where they were kept individually in well-ventilated and adequately lit housing of about $4 \mathrm{~m}^{2}$. A large tree trunk was set centrally, with branches on which the animals could remain seated or suspended. Twice daily the sloths were supplied with fresh branches and leaves of embaúba (Cecropia adenops) and water was available ad libitum.

A period of 7 days was allowed for adaptation to the new surroundings before the beginning of the collection of fecal samples. The collection was continued for approximately 12 weeks during which the sloths were examined daily regarding their pattern of motor activity, behavior and defecation. Weight and rectal temperature were recorded weekly.

Feces were collected on the day of voidance and samples placed in zip-lock bags and immediately frozen and stored at $-20^{\circ} \mathrm{C}$ until extraction by the method described by Brown et al. (6). The frozen samples were transported to the Laboratório de Dosagens Hormonais, Departamento de Medicina Veterinária e Zootecnia, Universidade de São Paulo, São Paulo, SP, Brazil, where the hormonal assays were conducted. Approximately $0.3 \mathrm{~g}$ of wet feces were boiled in 5 mL $90 \%$ ethanol (Etanol, P.A., Merck S.A., Indústrias Químicas, Rio de Janeiro, RJ, Brazil) for $20 \mathrm{~min}$. After centrifugation at $500 \mathrm{~g}$ for $15 \mathrm{~min}$, the supernatant was recovered and the pellet resuspended in $5 \mathrm{~mL} 90 \%$ ethanol, vortexed for $30 \mathrm{~s}$, and re-centrifuged. Ethanol supernatants were combined, and after dehydration under a stream of compressed air, were dissolved in $1.0 \mathrm{~mL}$ methanol (Metanol, P.A., Merck), and diluted in buffered solution $\left(13.8 \mathrm{~g} \mathrm{NaPO}_{4}, 9.0 \mathrm{~g} \mathrm{NaCl}\right.$, $1.0 \mathrm{~g}$ sodium azide, $1.0 \mathrm{~g}$ gelatin, and 1000 $\mathrm{mL}$ distilled water, $\mathrm{pH}$ 7.0). To obtain optimal concentrations for detection by the equipment the samples were diluted $1 / 5$ and $1 / 20$ for the metabolites of $\mathrm{E}_{2}$ and $\mathrm{P}_{4}$, respectively.

The amounts of fecal metabolites of $E_{2}$ and $\mathrm{P}_{4}$ were estimated by radioimmunoassay (RIA) using kits employed for quantitative evaluation of $E_{2}$ and $P_{4}$ in human serum (Coat-A-Count, Diagnostic Products Corporation, DPC Medlab ${ }^{\circledR}$, Los Angeles, CA, USA). Assays of reproductive hormone metabolites require validation in each animal species by demonstrating parallelism be- 
tween binding inhibition curves of fecal extract dilutions and the appropriate steroid standard (5). These kits were validated for use with sloth feces by the method of parallelism of depleted matrix. The hormonal depletion of a pool of samples was achieved with a solution of coal-dextran (6). Known amounts of the hormonal standards were added to the depleted matrix at dilutions that approached the points of the curve standard of the kits. The kits use ${ }^{125} \mathrm{I}$ as the hormone tracer and tubes are coated with rabbit antibodies to $\mathrm{E}_{2}$ and to $\mathrm{P}_{4}$.

The RIA for evaluation of fecal metabolites in sloths was validated by removing blood via venous puncture on 10 occasions on the same day as defecation. There is a rete mirabile present in the limbs of sloths, making cannulation of the blood vessels there extremely difficult. Thus, we used the method described by Wallace and Oppenheim (7) and Vogel et al. (8) for the removal of blood from Choloepus hofmannii. After swabbing with $70 \%$ alcohol, and applying a tourniquet, a puncture was made in the cephalic vein of a forelimb. About $3 \mathrm{~mL}$ of blood was collected without anesthesia on each occasion and transferred to a vial containing 0.1 $\mathrm{mL}$ of heparin $\left(20 \mathrm{OUCH} / \mathrm{mL}\right.$, Liquemine ${ }^{\circledR}$, Roche, Rio de Janeiro, RJ, Brazil). The plasma was separated by centrifugation at 3000 rpm (Excelsa 2; model 205N, FANEM Ltda., São Paulo, SP, Brazil) for $10 \mathrm{~min}$ and stored at $-20^{\circ} \mathrm{C}$ until analysis.

The plasma samples were thawed and the levels of $E_{2}$ and $P_{4}$ measured in the same laboratory where the fecal hormonal assays were carried out. The kit used to measure plasma levels of $\mathrm{E}_{2}$ in $B$. variegatus was the 3rd-generation estradiol RIA of Diagnostic Systems Laboratories, Inc., Webster, TX, USA. This kit uses estradiol ${ }^{125} \mathrm{I}$ and anti- $\mathrm{E}_{2}$ extracted from rabbits as the antiserum and has a sensitivity of $0.6 \mathrm{pg} / \mathrm{mL}$. The plasma levels of $\mathrm{P}_{4}$ were measured using the same solid phase as for the metabolites of this hormone. Data are reported as means \pm SD.
Statistical analysis was performed with the Statistica for Windows software, version 5.0 using the paired Student $t$-test and Pearson's correlation coefficient. The levels of fecal metabolites were compared by oneway ANOVA. Values were considered significant when the P value was less than 0.05 . Once the collection of feces and hormonal measurements had been completed, the animals were kept under observation until their release by IBAMA.

The initial weights (mean \pm SD) of the 4 sloths (SL) were $3.9 \pm 0.2 \mathrm{~kg}$ for SL01, $3.3 \pm$ $0.1 \mathrm{~kg}$ for SL02, $2.6 \pm 0.4 \mathrm{~kg}$ for SL03, and $3.9 \pm 0.2 \mathrm{~kg}$ for SL04. Throughout their captivity the sloths remained healthy and adapted well to their surroundings. Only the weight of SL03 showed a very significant change, increasing by more than $25 \%$ during its time under observation $(\mathrm{P}<0.05$, paired Student $t$-test). Body temperature is reported to vary between $28^{\circ}$ and $32^{\circ} \mathrm{C}$ in three-toed sloths (2). The temperature was recorded during a 12 -week period and averaged $32 \pm$ $1^{\circ} \mathrm{C}$.

It has been reported that food can take around 8 days to pass through the digestive tract of sloths (9). However, during the present study the sloths defecated, on average, twice weekly on alternate days $(2.4 \pm 0.4$ days). SL01 was observed for 184 days and defecated 65 times; both SL02 and SL03 were monitored for 143 days and defecated 42 and 62 times, respectively, and SL04, which was observed for 94 days, defecated 38 times. The mean frequency of defecation per week during this time was 2.5, 2.1, 2.1, and 2.9 times for SL01, SL02, SL03, and SL04, respectively. It was possible to gain a much better picture of hormonal changes over the period of observation than would have been possible if defecation had been only weekly.

The average percentages of cold recovery obtained for the metabolites of $\mathrm{E}_{2}$ and $\mathrm{P}_{4}$ were 78 and $73 \%$, respectively. The assay sensitivity, detected with a Packard Cobra 
Auto-Gamma counter (Canberra Packard, Meriden, CT, USA), was $2.42 \mathrm{pg} / \mathrm{mL}$ for the fecal metabolites of $E_{2}$ and $0.004 \mathrm{ng} / \mathrm{mL}$ for those of $\mathrm{P}_{4}$. The kits used were found to be specific with little cross-reactivity and the quality control samples and the intra- and inter-assay coefficients of variation (CV) were low, being less than 5 and $1.3 \%$, respectively. These values are clearly acceptable since, according to Brown et al. (6), the intra- and inter-assay $\mathrm{CV}$ should be less than 10 and $15 \%$, respectively, to be considered precise. The correlation coefficient for the curve was 0.993 for the fecal metabolites of $\mathrm{E}_{2}$ and 0.977 for the fecal metabolites of $\mathrm{P}_{4}$.

The plasma levels of the hormones showed correlation coefficients of 0.997 for $\mathrm{E}_{2}$ and 0.994 for $\mathrm{P}_{4}$. A significant correlation was found between the plasma levels of $\mathrm{E}_{2}$ and the levels of the fecal metabolites of the same hormone (Figure 1, $\mathrm{P}<0.05 ; \mathrm{r}=0.689$; $\mathrm{F}=7.23$; d.f. $=1.8, \mathrm{P}<0,05$, Pearson's correlation coefficient). Thus, these results confirm the validity of using extracts of sloth feces to measure the circulating levels of these metabolites during the estrous cycle. Fecal levels of the $\mathrm{P}_{4}$ metabolites were also correlated with plasma levels, although the sample number was small and the results can only be regarded as preliminary.

Although the profile of estradiol concentrations in the feces was similar to that found in plasma, it was not possible to determine the time lag between the secretion of the hormones by the ovary and/or placenta and the appearance of hormonal metabolites in the feces. In wild baboons (10), fecal ster-

Figure 1. Levels of estradiol $\left(E_{2}\right)$ in plasma and feces of Bradypus variegatus sloths.

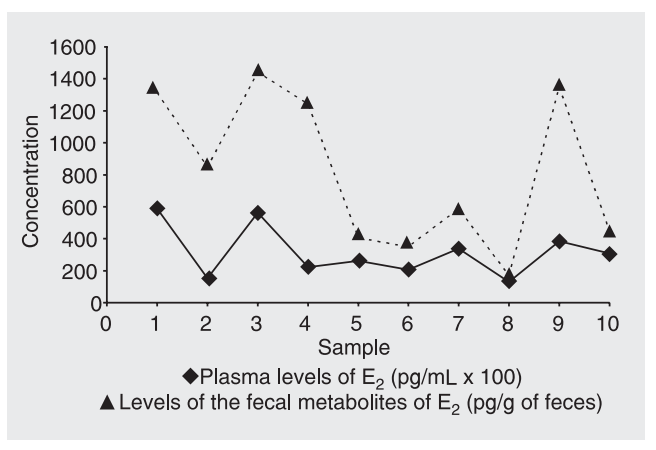

oids are excreted at intervals of $36 \mathrm{~h}$ after secretion, reflecting the duration of the passage of food through the gastrointestinal tract of this animal, which ranges from a few hours to several days. In sloths, in which the passage of food can take up to 8 days (9), the time lag is obviously much longer than in most other mammals. This information is important when attempting to determine the timing of physiological events such as ovulation or to test the relationship between hormone levels and patterns of behavior in wild animals. Fecal levels of the $\mathrm{P}_{4}$ metabolites also correlated with plasma levels, although the sample number was small and thus the results were not included here. While the present study has contributed substantially to our knowledge of ovarian activity in sloths, further investigations using sequential blood collections are required to determine the exact time lag between plasma hormone levels and their metabolites appearing in the feces.

Figure 2 shows the levels of the estradiol and progesterone metabolites measured in our studies. In 2 of the sloths (SL01 and SL02) no evidence of ovulation was detected, with no large peaks in the levels of the fecal metabolites of either $\mathrm{E}_{2}$ or $\mathrm{P}_{4}$ (Figure 2A,B,E,F). However, ovulation would appear to have taken place in SL03 and SL04 (Figure 2C,D, G,H, see arrows). In both sloths the elevated levels of $\mathrm{E}_{2}$ remained at a plateau for a considerable time and, when they did fall, this reduction was followed by a rise in the levels of $\mathrm{P}_{4}$ metabolites. After reaching a maximum, the levels of $\mathrm{P}_{4}$ metabolites fell in SL03 (Figure 2G) but remained elevated in SL04 (Figure $2 \mathrm{H}$ ) and were significantly higher $(\mathrm{P}<0.05$, one-way ANOVA) than those seen in the other three animals.

Figure $2 \mathrm{C}$ shows an increase in $\mathrm{E}_{2}$ metabolites (from 394.26 to $2237.43 \mathrm{pg} / \mathrm{g}$ wet feces) that occurred in SL03 around the 40th day of monitoring. The levels remained high for approximately 30 days, but then fell 

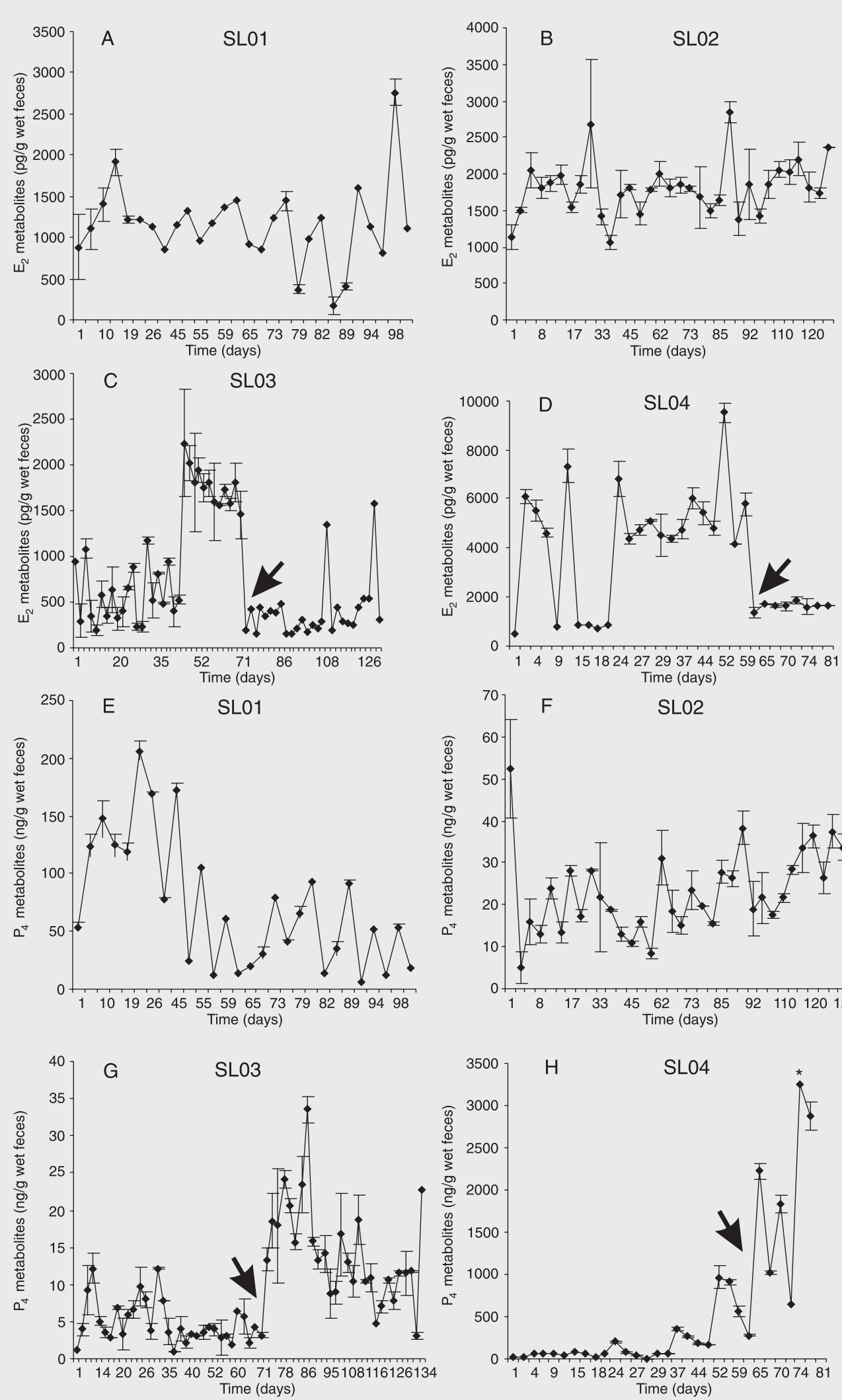
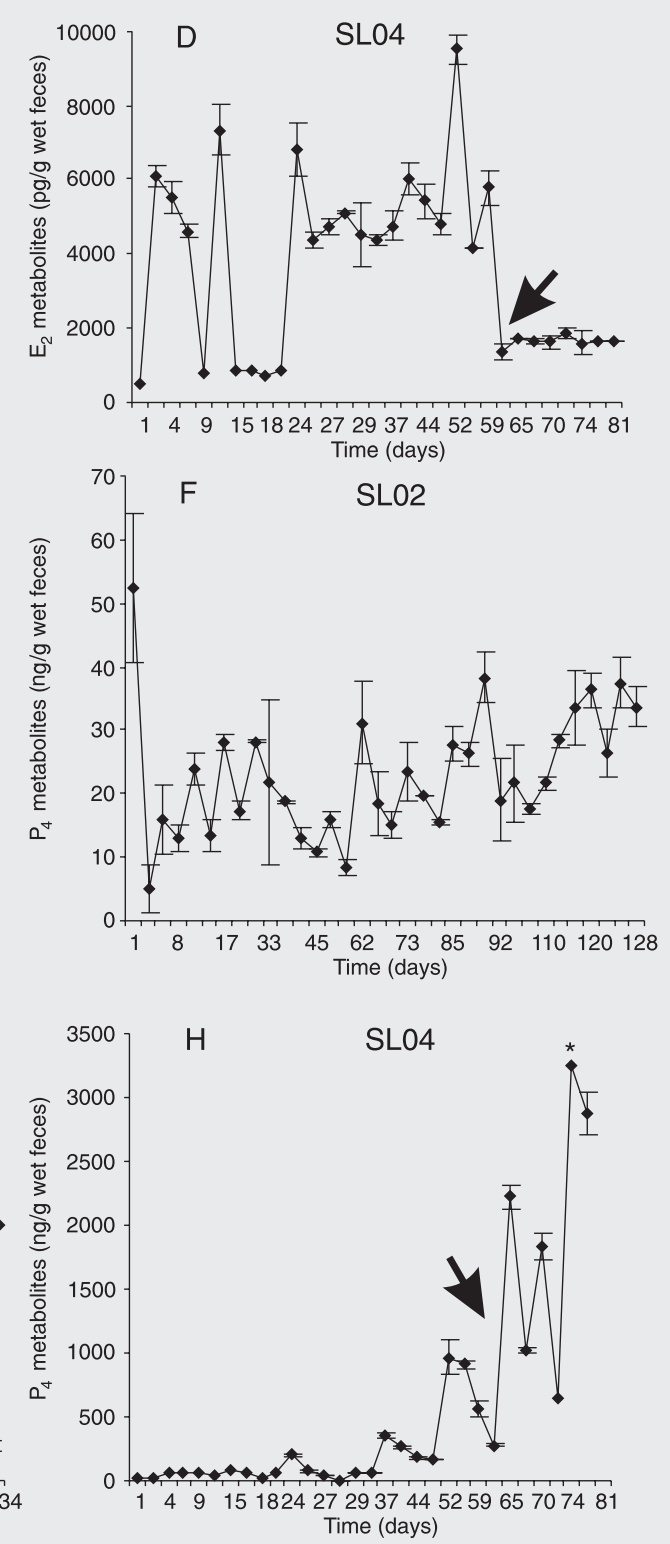

Figure 2. Individual levels of fecal metabolites of estradiol $\left(E_{2}\right)$ and progesterone $\left(\mathrm{P}_{4}\right)$ in Bradypus variegatus sloths (SL). Ovulation is indicated by an arrow. Data are reported as means \pm SD for three readings in each animal $(\mathrm{N}=4)$. ${ }^{*} \mathrm{P}<0.05 \mathrm{com}$ paring the levels of progesterone in SL04 with those seen in the other three animals (oneway ANOVA). 
abruptly on the $73 \mathrm{rd}$ day to $188.59 \mathrm{pg} / \mathrm{g}$ wet feces. This fall in $E_{2}$ metabolites occurred at much the same time when a very large increase occurred in $\mathrm{P}_{4}$ metabolites from 2.04 to $33.54 \mathrm{ng} / \mathrm{g}$ wet feces (Figure 2G). A peak in $\mathrm{P}_{4}$ metabolites occurred around the 90th day of monitoring (33.54 ng/g wet feces), after which they fell sharply and remained low $(3.08 \mathrm{ng} / \mathrm{g}$ wet feces) until the end of recording (Figure 2G). The results for this animal suggest that the interval between ovulations - the duration of the estrous cycle was over 60 days. Because only 4 female sloths were studied and each showed a different hormonal profile, it was not possible to deduce the mean duration of the estrous cycle in this study.

In SL04 (Figure 2D) $\mathrm{E}_{2}$ metabolites rose from the 22nd day of monitoring (from 818.16 to $6713.26 \mathrm{pg} / \mathrm{g}$ wet feces) and remained elevated until around the 37th day. From around the 59th day $\mathrm{E}_{2}$ levels fell abruptly to $1356.79 \mathrm{pg} / \mathrm{g}$ wet feces, accompanied by a rise (from 274.10 to $722.86 \mathrm{ng} /$ $\mathrm{g}$ wet feces) in $\mathrm{P}_{4}$ metabolites (Figure $2 \mathrm{H}$ ). Unlike the situation for SL03, in SL04 $\mathrm{P}_{4}$ metabolites remained high throughout the period monitored, reaching a peak of 3242.68 $\mathrm{ng} / \mathrm{g}$ wet feces on the 74th day (Figure $2 \mathrm{H}$ ). This would suggest that ovulation occurred and was followed by the formation of a functional corpus luteum.

During the period the animals were kept before their release by IBAMA, SL04 gave birth to a healthy offspring, which could explain the high levels of hormonal metabolites found in her feces (Figure 2H). It would seem reasonable to conclude that the placenta was the source of these hormones.

Recently Taube et al. (1) estimated gestation in B. variegatus to last approximately 6 months. The high levels of $\mathrm{E}_{2}$ and $\mathrm{P}_{4}$ metabolites seen in the feces of SL04 suggest that this female was already pregnant when supplied by IBAMA in the middle of December 2003, since thereafter it remained isolated without contact with males. Since birth did not take place until July 2004, it is reasonable to conclude that the period of gestation is over 7 months. SL02 was brought in with a newborn, indicating a recent gestation that might explain why no further ovulations were detected during the period of observation. Wetzel (11) argued that specimens of $B$. variegatus may be considered adult when their weight reaches $3.5 \mathrm{~kg}$. However, in Recife a pregnant female weighing only $3.3 \mathrm{~kg}$ and carrying a small fetus was reported in 1994 by Gilmore DP and Da Costa CP (unpublished observations). Moreover, SL02, accompanied by a small young when supplied by IBAMA, also weighed only $3.3 \mathrm{~kg}$.

The main objective of the present study, i.e., to demonstrate that a noninvasive technique is reliable for determining the levels of gonadal steroids in the three-toed sloth, has been achieved, making it possible for the first time to study ovarian function in sloths and opening possibilities for future studies on the estrous cycle of this animal. Currently the manned sloth (B. torquatus) is highly endangered. A noninvasive study such as that carried out on B. variegatus could shed further light on the reproduction of this species also.

\section{Acknowledgments}

We thank Dr. Adelmar Afonso de Amorim Junior, Departamento de Anatomia, Universidade Federal de Pernambuco, Recife, PE, Brazil, and Dr. Marleyne Joe Afonso Accioly Lins Amorim, Departamento de Morfologia e Fisiologia Animal, Universidade Federal Rural de Pernambuco, Recife, $\mathrm{PE}$, Brazil, for teaching us the surgical techniques necessary for blood collection. 


\section{References}

1. Taube E, Keravec J, Vié J-C et al. (2001). Reproductive biology and postnatal development in sloths, Bradypus and Choloepus: review with original data from the field (French Guiana) and from captivity. Mammal Review, 31: 173-188.

2. Goffart M (1971). Function and Form in the Sloth. Pergamon Press, Oxford, UK.

3. Gilmore DP, Da Costa CP \& Duarte DPF (2000). An update on the physiology of two- and three-toed sloths. Brazilian Journal of Medical and Biological Research, 33: 129-146.

4. Gilmore DP, Da Costa CP, Valenca M et al. (1991). Effects of exogenous LHRH on plasma LH and sex steroid levels in the threetoed sloth Bradypus tridactylus. Medical Science Research, 19: 333-335.

5. Kapke CP, Arcese P, Ziegler TE et al. (1999). Estradiol and progesterone metabolite concentration in white-tailed deer (Odocoileus virginianus) feces. Journal of Zoo and Wildlife Medicine, 30: 361371.

6. Brown JL, Wasser SE, Wildt DE et al. (1994). Comparative aspects of steroid hormone metabolism and ovarian activity in felids, meas- ured noninvasively in feces. Biology of Reproduction, 51: 776-786.

7. Wallace C \& Oppenheim YC (1996). Hematology and serum chemistry profiles of captive Hoffmann's two-toed sloths (Choloepus hofmannii). Journal of Zoo and Wildlife Medicine, 27: 339-345.

8. Vogel I, Vié J-C, Thoisy B et al. (1999). Hematological and serum chemistry profiles of free-ranging southern two-toed sloths in French Guiana. Journal of Wildlife Diseases, 35: 531-535.

9. Montgomery GG \& Sunquist ME (1978). Habitat selection and use by two-toed and three-toed sloths. In: Montgomery GG (Editor), Ecology of Arboreal Folivores. Smithsonian University Press, Washington, DC, USA, 329-359.

10. Wasser SK (1994). Reproductive function in wild baboons measured by fecal steroids: Implications for biomedicine and conservation. American Journal of Primatology, 33: 247-248.

11. Wetzel R (1985). The identification and distribution of recent Xenarthra (= Edentata) of Brazil. In: Montgomery GG (Editor), Ecology of Arboreal Folivores. Smithsonian University Press, Washington, DC, USA, 5-21. 